\title{
Disease progression of HIV-1 infection in symptomatic and asymptomatic seroconverters in Osaka, Japan: a retrospective observational study
}

Dai Watanabe ${ }^{* *}$, Sachiko Suzuki', Misa Ashida', Yuka Shimoji², Kazuyuki Hirota', Yoshihiko Ogawa', Keishiro Yajima ${ }^{1}$, Daisuke Kasai ${ }^{1}$, Yasuharu Nishida ${ }^{1}$, Tomoko Uehira ${ }^{1}$ and Takuma Shirasaka ${ }^{1}$

\begin{abstract}
Background: Estimates of the interval from HIV-1 infection to disease progression may be affected by selection bias, and data concerning asymptomatic early seroconverters are limited. We examined the interval until disease progression in HIV-1 seroconverters in whom the timing of infection could be estimated within 1 year before diagnosis.

Methods: Subjects included newly diagnosed patients at Osaka National Hospital between 2003 and 2010 who had either (1) symptomatic acute HIV-1 infection with a negative or intermediate reaction on Western blotting and a positive reaction on an HIV RNA test (symptomatic acute group) or (2) a positive reaction on Western blotting at diagnosis and a $<1$-year interval from the last negative HIV test until the first positive test. The latter was divided into symptomatic recent or asymptomatic recent groups based on the presence or absence, respectively, of any transient fever between the last negative and first positive tests. Disease progression was defined as a fall in the CD4 count to $<350$ cells/microL on 2 consecutive tests, the start of anti-HIV therapy, or the onset of AIDS-indicator diseases. Information was retrospectively collected from medical records.

Results: Subjects included 210 patients: 91 in the symptomatic acute group, 72 in the symptomatic recent group, and 47 in the asymptomatic recent group. In the symptomatic acute (0.8 years) and symptomatic recent (2.2 years) groups, the Kaplan-Meier estimate of median interval until disease progression was significantly shorter than that in the asymptomatic recent group (2.9 years). Multivariate analysis by Cox's proportional hazards test showed that the symptomatic acute group (vs. asymptomatic recent group: hazard ratio: 1.93; 95\% confidence interval: 1.14-3.36; $p=0.0140$ ) and a baseline CD4 count of $<400$ cells/microL (hazard ratio: $3.88 ; 95 \%$ confidence interval: 2.57-5.96; $p<0.0001)$ were independent prognostic factors associated with early disease progression.
\end{abstract}

Conclusions: Symptomatic seroconversion was associated with early disease progression. Furthermore, the estimated median interval until the CD4 count was $<350 \mathrm{cells} / \mathrm{microL}$ was only 2.9 years even in patients with asymptomatic seroconversion. These results suggest the importance of early diagnosis in early seroconverters.

Keywords: HIV-1 infection, Seroconverters, Disease progression

\footnotetext{
*Correspondence: dai@onh.go.jp

${ }^{1}$ AIDS Medical Center, National Hospital Organization Osaka National

Hospital, 2-1-14 Hoenzaka, Chuo-ku, Osaka City, Osaka 540-0006, Japan

Full list of author information is available at the end of the article
} 


\section{Background}

Studies in the late 1980s reported that the asymptomatic phase persisted for about 10 years in patients infected with human immunodeficiency virus (HIV)-1 [1-4]. However, various observational studies and metaanalyses have indicated that the baseline CD4-positive T-lymphocyte count (CD4 cell count) of the patients infected with HIV-1 in recent years is lower than that in previous studies, and that the plasma HIV-1-RNA level at the set point is higher [5-10], suggesting the possibility that HIV-1 has become more virulent and the asymptomatic phase has been shorter $[11,12]$.

After primary infection with HIV-1, symptoms such as fever, lymph node swelling, and headache appear in $40 \%-90 \%$ of patients [13]. Fever is the most common symptom related to primary HIV-1 infection [14-16]. A cohort study involving patients with symptomatic acute HIV-1 infection is one way to observe and evaluate the spontaneous course of HIV-1 infection. However, there are some limitations regarding observational studies involving patients with symptomatic acute HIV-1 infection. In these patients, the disease progression is more rapid than in those with asymptomatic acute HIV-1 infection [17-20]. In addition, the severity of acute HIV-1 infection is also associated with disease progression $[15,16,18]$. Therefore, the spontaneous history in patients with symptomatic acute HIV-1 infection does not always reflect that of HIV-1 infection overall. In a cohort study involving early HIV-1 seroconverters, the proportion of patients with symptoms was also high, suggesting the presence of a selection bias $[12,18]$.

With the appearance of new anti-HIV drugs and an accumulation of evidence, it has been recommended that antiretroviral therapy (ART) should be introduced in patients with a high CD4-positive T lymphocyte count (CD4 cell count). In Japanese guidelines, the CD4 cell count cutoff for the start of ART also increased from 200 to 350 cells $/ \mu \mathrm{L}$ in 2008 and then to 500 cells $/ \mu \mathrm{L}$ in 2013. However, the estimated interval from HIV infection until the CD4 cell count decreases to 350 cells $/ \mu \mathrm{L}$ is still important for evaluating the timing of ART initiation. Concerning recent reports $[5,16,20-27]$ of the estimated interval until disease progression, limitations of selection bias may be present as described above. In addition, data concerning asymptomatic early seroconverters are limited. We therefore focused on the characteristics of HIV-1 seroconverters both with and without symptoms related to primary HIV-1 infection. In this study, patients newly diagnosed based on positive reactions on Western blotting were investigated. Those in whom the timing of HIV-1 infection could be estimated to have been within 1 year before the HIV-1 infection diagnosis were divided into 2 groups with respect to the presence or absence of a history of fever between the last negative and first positive tests. We examined the characteristics by comparing the clinical course between these 2 groups and patients diagnosed with symptomatic acute HIV-1 infection.

\section{Results}

Patient groups

Of 1199 patients newly diagnosed with HIV-1 infection between 2003 and 2010 at the National Hospital Organization Osaka National Hospital, in 210, the timing of HIV-1 infection could be estimated within 1 year before their diagnosis. Ninety-five symptomatic patients had a negative or intermediate reaction detected on Western blotting at the time of HIV-1 infection diagnosis, and the polymerase chain reaction (PCR) method showed a positive reaction. Of these, 4 were diagnosed with chronic infection based on the changes in the Western blotting results, clinical course, and absence of a recent risk of infection. Therefore, 91 were diagnosed with symptomatic acute HIV infection (symptomatic acute group). In 119 patients, a positive reaction was detected on Western blotting at the time of HIV-1 infection diagnosis and the interval from the last negative test until the first positive test was $\leq 1$ year (recent group). Of these, 72 reported having a transient fever between the last negative and first positive tests (symptomatic recent group). The other 47 patients were assigned to the asymptomatic recent group.

\section{Patient characteristics and comparisons among symptomatic acute, symptomatic recent, and asymptomatic recent groups}

Patient characteristics are shown in Table 1. The demographic and clinical characteristics of the subjects were compared among the symptomatic acute, symptomatic recent, and asymptomatic recent groups. There were no differences in the age or estimated route of infection among these 3 groups. In the symptomatic acute and symptomatic recent groups, the proportion of patients diagnosed in the late phase (2007-2010) was higher than that of patients diagnosed in the early phase (20032006). In the symptomatic recent group, 46 patients (64\%) consulted a hospital for fever between the last negative and first positive tests. However, no HIV test was performed in any patient. The interval from the last negative test until the first positive test was compared between the symptomatic recent and asymptomatic recent groups. In the former (median 7.1 months), it was significantly shorter than in the latter (median 10.1 months), suggesting that a diagnosis of HIV infection was made earlier in the symptomatic recent group. Information regarding HIV-1 subtype was available in 111 of 210 participants. The most common subtype was B $(n=108)$, followed by CRF_01AE $(n=3)$. The 
Table 1 Demographic and clinical characteristics of participants

\begin{tabular}{|c|c|c|c|c|}
\hline Characteristic & $\begin{array}{l}\text { Symptomatic acute } \\
\text { group }\end{array}$ & $\begin{array}{l}\text { Symptomatic recent } \\
\text { group }\end{array}$ & $\begin{array}{l}\text { Asymptomatic recent } \\
\text { group }\end{array}$ & $\begin{array}{l}\mathrm{p} \\
\text { value }\end{array}$ \\
\hline Number of participants & 91 & 72 & 47 & \\
\hline Age at first visit (y), median [IQR] & $33[28-38]$ & $30[25-35]$ & $31[24-36]$ & 0.0841 \\
\hline Men, n (\%) & 91 (100\%) & $69(97 \%)$ & 47 (100\%) & 0.0387 \\
\hline \multicolumn{5}{|l|}{ Estimated route of transmission, n (\%) } \\
\hline Homosexual & 79 (87\%) & $66(92 \%)$ & $43(92 \%)$ & \multirow[t]{3}{*}{0.3234} \\
\hline Heterosexual & $9(10 \%)$ & $6(8 \%)$ & $2(4 \%)$ & \\
\hline Unknown & $3(3 \%)$ & $0(0 \%)$ & $2(4 \%)$ & \\
\hline \multicolumn{5}{|l|}{ HIV-1 subtype } \\
\hline B & $41(45 \%)$ & $40(56 \%)$ & $27(57 \%)$ & \multirow[t]{3}{*}{0.0983} \\
\hline CRF01_AE & $0(0 \%)$ & $1(1 \%)$ & $2(4 \%)$ & \\
\hline Not determined & $50(55 \%)$ & $31(43 \%)$ & $18(38 \%)$ & \\
\hline \multicolumn{5}{|l|}{ Nationality, n (\%) } \\
\hline Japanese & 89 (98\%) & $70(97 \%)$ & $47(100 \%)$ & \multirow[t]{2}{*}{0.3490} \\
\hline Other & $2(2 \%)$ & $2(2 \%)$ & $0(0 \%)$ & \\
\hline \multicolumn{5}{|l|}{ Calendar year at diagnosis, (\%) } \\
\hline $2007-2010$ & $65(71 \%)$ & $45(63 \%)$ & $20(43 \%)$ & \multirow[t]{2}{*}{0.0044} \\
\hline $2003-2006$ & $26(29 \%)$ & $27(37 \%)$ & $27(57 \%)$ & \\
\hline \multicolumn{5}{|l|}{$\begin{array}{l}\text { Medical exam between last negative and first positive test, } \\
\mathrm{n}(\%)\end{array}$} \\
\hline No & $3(3 \%)$ & $26(36 \%)$ & $47(100 \%)$ & \multirow[t]{3}{*}{$<0.000$} \\
\hline Outpatient & $28(31 \%)$ & $36(50 \%)$ & $0(0 \%)$ & \\
\hline Hospitalization & $60(66 \%)$ & $10(14 \%)$ & $0(0 \%)$ & \\
\hline $\begin{array}{l}\text { Interval between last negative and first positive test (mo), } \\
\text { median [IQR] }\end{array}$ & & $7.1[4.1-10.2]$ & $10.1[6.1-11.7]$ & 0.0472 \\
\hline Baseline CD4 cell count (cells/ $\mu \mathrm{L}$ ), median [IQR] & $359[243-464]$ & $353[257-481]$ & $445[353-526]$ & 0.0323 \\
\hline $\begin{array}{l}\text { Percentage of patients with CD4 cell count }<400 \text { cells/ } \mu \mathrm{L}, \mathrm{n} \\
(\%)\end{array}$ & $54(59 \%)$ & $43(60 \%)$ & $15(31 \%)$ & 0.0035 \\
\hline Baseline HIV-1 RNA level (copies/mL), median [IQR] & 470000 [52000-270000] & $32000[6900-74800]$ & 21000 [12000-66000] & $<0.0001$ \\
\hline $\begin{array}{l}\text { Percentage of patients with HIV-1 RNA level } \geq 50000 \text { copies/ } \\
\mathrm{mL}, \mathrm{n}(\%)\end{array}$ & $69(76 \%)$ & $26(36 \%)$ & $14(30 \%)$ & $<0.0001$ \\
\hline
\end{tabular}

Abbreviation: IQR, interquartile range

percentage of patients with subtype B HIV-1 infection was not statistically different among the symptomatic acute, symptomatic recent, and asymptomatic recent groups (Table 1) and was not changed from the early phase $(2003-2006,55 \%)$ to the late phase $(2007-2010$, $49 \%)(\mathrm{p}=0.1900)$.

\section{Comparison of baseline CD4 cell count and plasma HIV-1 RNA level}

We examined the CD4 cell count and viral level on the initial consultation. Overall, the median CD4 cell count and plasma HIV-1 RNA level were 383 cells $/ \mu \mathrm{L}$ and 51,900 copies $/ \mathrm{mL}$, respectively. The proportion of patients with a CD4 cell count of $<400$ cells $/ \mu \mathrm{L}$ and that of patients with a plasma HIV-1-RNA level of $\geq 50,000$ copies $/ \mathrm{mL}$ are presented in Table 1 . In the symptomatic acute and symptomatic recent groups, the proportions of patients with a baseline CD4 cell count of $<400$ cells/ $\mu \mathrm{L}$ were higher than that in the asymptomatic recent group (symptomatic acute vs. asymptomatic recent: $\mathrm{p}<$ 0.01 ; symptomatic recent vs. asymptomatic recent: $\mathrm{p}<$ 0.01 ). Furthermore, the proportion of patients with a baseline plasma HIV-1-RNA level of $\geq 50,000$ copies/mL was the highest in the symptomatic acute group among the 3 groups (symptomatic acute vs. asymptomatic recent: $\mathrm{p}<0.001$; symptomatic acute vs. symptomatic recent: $\mathrm{p}<0.001)$.

\section{Estimated interval from HIV-1 infection until disease progression}

We examined the interval from the estimated timing of infection until disease progression. Twelve patients 
enrolled in a clinical study, in whom ART was started regardless of their CD4 cell counts, were excluded from the analysis. Of the 198 patients, 119 met the criteria for disease progression during the follow-up period (median 0.78 years). Of these, 96 patients showed a CD4 cell count of $<350$ cells $/ \mu \mathrm{L}$ on 2 consecutive tests. In the other 19 patients who had a CD4 cell count of $<350$ cells $/ \mu \mathrm{L}$ on at least 1 test, ART was started ( 9 in the acute symptomatic phase and 6 in the chronic asymptomatic phase) or AIDSindicator diseases were diagnosed before the above criterion was met. In the remaining 4 , although the CD4 cell count did not reach $<350$ cells $/ \mu \mathrm{L}$ on either test, ART was started for prevention of partner infection, HBV infection, thrombocytopenia, and HIV infection-related malaise in each patient. In the symptomatic acute group, in only one of the patients with a CD4 cell count of $<350$ cells $/ \mu \mathrm{L}$ on the first and second tests did the CD4 cell count return to $\geq 350$ cells $/ \mu \mathrm{L}$ within the next 3 months. Using the Kaplan-Meier method, we estimated the interval from the estimated timing of infection until disease progression. In the cohort overall, the median interval until disease progression was 1.9 years. In the symptomatic acute, symptomatic recent, and asymptomatic recent groups, it was $0.8,2.2$, and 2.9 years, respectively (Figure 1), showing significant differences (symptomatic acute vs. symptomatic recent: $\mathrm{p}<0.001$; symptomatic acute vs. asymptomatic recent: $\mathrm{p}<0.001$; symptomatic recent vs. asymptomatic recent: $\mathrm{p}<0.05)$. Using Cox's proportional hazards model, we investigated factors involved in early disease progression (Table 2). On univariate analysis, a baseline CD4 cell count of $<400$ cells $/ \mu \mathrm{L}$, and belonging to the symptomatic acute group were significant factors. Multivariate analysis showed that the baseline CD4 cell count and belonging to the symptomatic acute group were

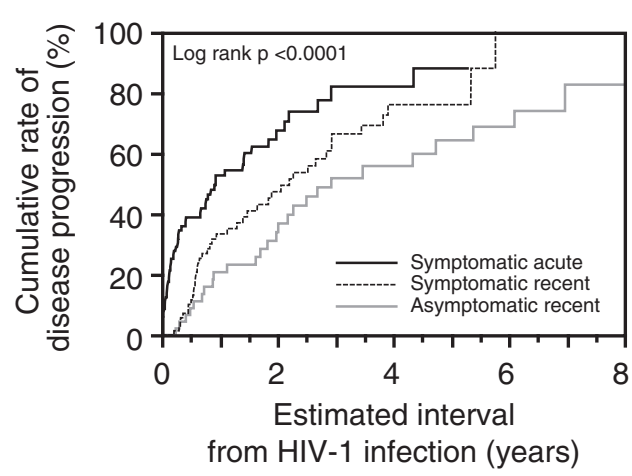

No. at risk

$\begin{array}{lllllll}\text { Symptomatic acute } & 81 & 29 & 11 & 4 & 3 & 1\end{array}$ $\begin{array}{lllllll}\text { Symptomatic recent } & 71 & 39 & 25 & 12 & 5 & 3\end{array}$ $\begin{array}{lllllllll}\text { Asymptomatic recent } 46 & 32 & 23 & 16 & 11 & 8 & 6 & 2 & 1\end{array}$

Figure 1 Kaplan-Meier plot of the cumulative rate of disease progression in the study participants. Comparison of the cumulative rate of disease progression among the symptomatic acute, symptomatic recent, and asymptomatic recent groups. independent factors. To verify the results of multivariate analysis, we conducted subgroup analysis by stratification of the CD4 cell count on the initial consultation (Figure 2). In the symptomatic acute group, disease progression was observed in the early stage regardless of the baseline CD4 cell count. However, the interval until disease progression was similar between the symptomatic recent and asymptomatic recent groups through stratification. These results showed that the interval from HIV infection until disease progression was associated with the CD4 cell count on the initial consultation, a diagnosis of acute HIV infection, and fever suggestive of primary infection with HIV-1 and that the former 2 were independent factors.

\section{Discussion}

This study was conducted in HIV-1 seroconverters in Osaka (Japan) in whom the timing of infection could be estimated within 1 year before diagnosis. Initially, as important observation points, disease progression was noted in the early stage in symptomatic HIV-1 seroconverters. In those diagnosed in the acute stage of HIV-1, the median interval until disease progression was only 0.8 years (Figure 1). Although some studies have estimated the interval from infection until the CD4 cell count reaches $<350$ cells $/ \mu \mathrm{L}$ in patients with acute HIV1 infection [5,16,20-24,26,27], it is difficult to compare the results among different cohorts due to differences in the definition of acute HIV-1 infection and disease progression or patient background. However, similar median intervals have been reported from Japan $(<1$ year) [16], Holland ( $<1$ year) [24], and Germany (8.3 months) [26], although some reports showed longer median intervals than this report does $[5,20,21,23,27]$. The reasons suggested for early disease progression include host-related factors such as genetic background, route of infection, and social background; viral factors such as subtype and escape mutations; and the possibility of a selection bias in which severe-status patients were predominantly enrolled in the study $[28,29]$. The mechanism of early disease progression remains to be clarified, but it must be considered that disease progression is rapid in patients with symptomatic acute HIV-1 infection.

Even in patients without primary infection symptoms (asymptomatic recent group), the median interval from infection until disease progression was 2.9 years. In a large-scale observational study involving 18,495 seroconverters, the interval from infection until the CD4 cell count reached $<350$ cells $/ \mu \mathrm{L}$ was estimated to be 4.19 years [25]. However, approximately $50 \%$ of the study subjects had been diagnosed with HIV-1 infection before 1996. The subjects included patients with symptomatic acute HIV infection. Therefore, although the interval from infection until the CD4 cell count reached $<350$ cells $/ \mu \mathrm{L}$ is longer than what we report here, a 
Table 2 Association with early disease progression in early HIV-1 seroconverters

\begin{tabular}{|c|c|c|c|c|c|c|}
\hline & \multicolumn{3}{|c|}{ Univariate results } & \multicolumn{3}{|c|}{ Multivariate results } \\
\hline & $\mathrm{HR}$ & $95 \% \mathrm{Cl}$ & $p$ value & HR & $95 \% \mathrm{Cl}$ & $p$ value \\
\hline Age ( $\geq 40$ vs. $<40)$ & 1.21 & $0.73-1.93$ & 0.4411 & 1.25 & $0.75-2.00$ & 0.3739 \\
\hline Calendar year at diagnosis (2007-2010 vs. 2003-2006) & 1.36 & $0.93-2.03$ & 0.1170 & 1.26 & $0.83-1.93$ & 0.2823 \\
\hline With baseline CD4 cell count $<400$ cells $/ \mu \mathrm{L}$ & 4.02 & $2.70-6.08$ & $<0.0001$ & 3.88 & $2.57-5.96$ & $<0.0001$ \\
\hline \multicolumn{7}{|l|}{ Group } \\
\hline Asymptomatic recent group & 1 & & & 1 & & \\
\hline Symptomatic recent group & 1.62 & $0.97-2.74$ & 0.0621 & 1.12 & $0.67-1.93$ & 0.6772 \\
\hline Symptomatic acute group & 2.95 & $1.79-4.99$ & $<0.0001$ & 1.93 & $1.14-3.36$ & 0.0140 \\
\hline
\end{tabular}

Abbreviations: $\mathrm{HR}$, hazard ratio; $\mathrm{Cl}$, confidence interval.

direct comparison between the previous report [25] and ours is not possible.

Of the 119 patients with positive reactions on Western blotting at the time of HIV-1 infection diagnosis, symptoms possibly related to primary infection with HIV-1

\section{A}

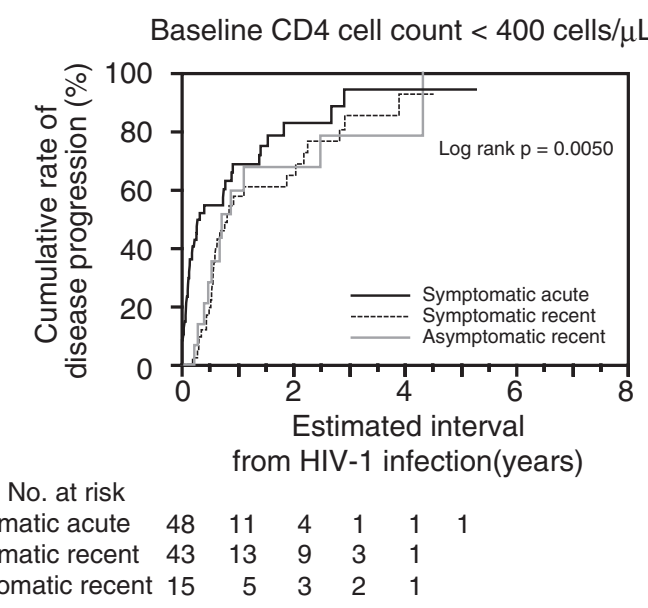

B

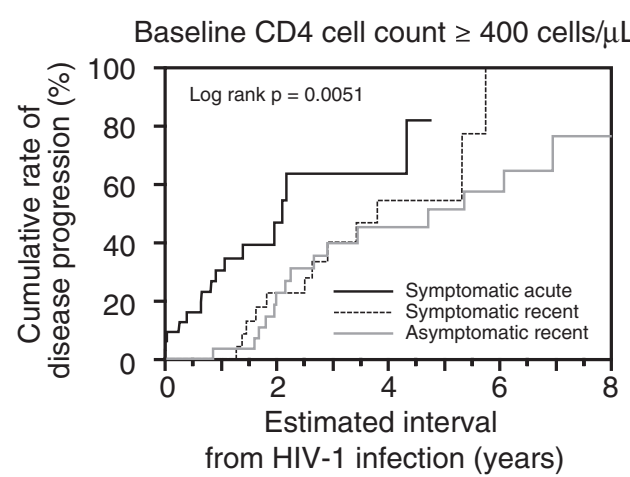

No. at risk

$\begin{array}{llllll}\text { Symptomatic acute } & 33 & 18 & 7 & 3 & 2\end{array}$

$\begin{array}{lllllll}\text { Symptomatic recent } & 28 & 26 & 16 & 9 & 4 & 3\end{array}$

$\begin{array}{llllllllll}\text { Asymptomatic recent } & 31 & 27 & 20 & 14 & 10 & 8 & 6 & 2 & 1\end{array}$

Figure $\mathbf{2}$ Kaplan-Meier plot of the cumulative rate of disease progression stratified with the CD4 cell count. (A) Patients with a CD4 cell count of $<400$ cells/ $\mu \mathrm{L}$ on the initial consultation. (B) Patients with a baseline CD4 cell count of 400 cells/ $\mu \mathrm{L}$ or more. were observed in 72. However, this figure may include an error. Although patients were questioned about a history of fever at the initial consultation, fever is not always related to primary HIV-1 infection. Furthermore, we cannot rule out the possibility that some patients could not recollect the appearance of symptoms related to primary infection and were assigned to the asymptomatic recent group. However, when analyzing the HIV-1 RNA level (Table 1) and interval from infection until disease progression (Figure 1), the symptomatic acute and asymptomatic recent groups showed opposite characteristics. Those of the symptomatic recent group were intermediate between the other 2 groups. Based on these results, we believe the majority of participants were assigned to the correct groups. Several possibilities may explain why the symptomatic acute and symptomatic recent groups showed different disease progression. One possible reason is the difference in disease severity because the proportion of patients who were hospitalized in the symptomatic acute group was higher than that in the symptomatic recent group (Table 1). However, we cannot exclude the possibility that recall bias, as mentioned above, may have affected this difference.

As shown in Table 1, the interval from the last negative test until the first positive test in the symptomatic recent group was significantly shorter than in the symptomatic recent group. This suggests the possibilities that the development of fever motivated those who recognize the risk of HIV-1 infection to undergo voluntary HIV testing and that the true seroconversion date with symptomatic seroconverters would be closer to the date of the first positive test rather than the date of the last negative test. These possibilities were also indicated by the recent report estimating the date of infection for HIV-1 infected patients using the HIV-1-specific immunoglobulin G (IgG) levels measured by the IgGcapture BED-enzyme immunoassay [30].

A limitation of this study is that it was a retrospective analysis involving a limited number of patients in a single institution. We are also aware of possible limitations of selection and recall biases in this study. Selection of 
the patients with fever related to the primary HIV-1 infection could be a potential source of selection bias. However, the data presented in this study are consistent with the results of previous studies. Patients diagnosed with acute HIV-1 infection showed disease progression in the early stage. Fever related to primary HIV-1 infection encouraged patients undergo HIV testing. Additionally, disease progression may be observed within a relatively short period even in asymptomatic early-infection patients.

\section{Conclusions}

Symptomatic HIV-1 seroconversion was associated with early disease progression, especially in patients with symptomatic acute HIV-1 infection, with a median interval until disease progression of only 0.8 years. Furthermore, the estimated median period during which the CD4 cell count was $<350$ cells $/ \mu \mathrm{L}$ was only 2.9 years even in patients with asymptomatic seroconversion. These results suggest the importance of early diagnosis in early HIV-1 seroconverters.

\section{Methods \\ Case selection}

This study was conducted at the National Hospital Organization Osaka National Hospital, a major hospital for HIV infection in Japan, located in the center of Osaka. Subjects included newly diagnosed patients with HIV-1 infection who consulted this hospital for the first time between 2003 and 2010 and who met 1 of the following 2 criteria: (1) a negative or intermediate reaction detected on Western blotting at the time of HIV-1 infection diagnosis and a positive PCR, leading to a diagnosis of symptomatic acute HIV-1 infection (symptomatic acute group) or (2) a positive reaction detected on Western blotting at the time of HIV-1 infection diagnosis and a $<1$-year interval from the final negative HIV test until the first positive HIV test (recent groups). The protocol of this study was approved by the Ethics Review Board of the National Hospital Organization Osaka National Hospital (Approval No. 0913).

\section{Measurement of the CD4 cell count, plasma HIV-1 RNA level, and Western blotting}

The CD4 cell count was measured by flow cytometry using the single-platform method. Peripheral blood $(100 \mu \mathrm{L})$ was incubated with $10 \mu \mathrm{L}$ of CYTO-STAT tetraCHROME reagent (Beckmann Coulter, Miami, FL) containing CD45-FITC/CD4-RD1/CD8-ECD/CD3-PC5 monoclonal antibodies. After erythrocyte hemolysis and cell fixation with the whole blood lysing reagent Kit (Beckmann Coulter), $100 \mu \mathrm{L}$ of Flow-Count fluorospheres were added to the sample, and the absolute $\mathrm{CD} 45+\mathrm{CD} 3+\mathrm{CD} 4+\mathrm{CD} 8$ - cell counts were measured using a Cytomics FC500 system (Beckmann Coulter).
The plasma HIV-1 RNA level was determined using the reverse-transcription PCR method (COBAS AMPLICOR HIV-1 test or COBAS TaqMan HIV-1 test; Roche Molecular Diagnostics, Branchburg, NJ). The CD4 cell count and plasma HIV-1 RNA level were measured at 1to 4-month intervals. For Western blotting for HIV-1, LAV Blot I (Bio-Rad Laboratories, Hercules, CA) was used. Interpretation of the results was performed according to the criteria established by the World Health Organization.

Definition of the symptomatic acute, symptomatic recent, and asymptomatic recent groups and comparison of clinical information on the initial consultation among the groups

The symptomatic acute group was defined as described above. Patients meeting conditions for both the symptomatic acute and recent groups were assigned to the symptomatic acute group. In the recent group, any selfreported history of a transient fever was investigated at the initial consultation in our hospital. Fever was defined as a body temperature of $38^{\circ} \mathrm{C}$ or higher. When a definitive diagnosis of a disease that causes fever was made, the patient was excluded from a history of fever. Patients who recollected having a transient fever between the last negative and first positive tests for HIV infection were assigned to the symptomatic recent group, and those who did not were assigned to the asymptomatic recent group. Information on the age, sex, nationality, estimated route of infection, year of diagnosis, previous hospital consultations, CD4 cell count, and plasma HIV-1 RNA level was collected from medical records and compared among the 3 groups.

\section{Estimation of the timing of HIV-1 infection and interval from infection until disease progression}

In the symptomatic acute group, the timing of infection was estimated to be 1 month before a diagnosis of HIV1 infection was made. In the recent groups, the midpoint between the last negative and first positive tests was regarded as the estimated timing of infection. The timing of disease progression was defined as the earliest date on which the CD4 cell count was less than 350 cells $/ \mu \mathrm{L}$ on 2 consecutive tests conducted at more than 1 month apart, the start of ART, or the onset of an AIDS-indicator disease. In patients in whom the annual frequency of testing for the CD4 cell count and plasma HIV-1 RNA level became <3, follow-up was completed on the final day of testing. The interval from the estimated timing of infection until disease progression was calculated using the Kaplan-Meier method. For significance tests, the log-rank test was performed. When there was a significant difference, adjustment was conducted using Holm's correction, and multiple tests were 
performed. For multivariate analysis, Cox's proportional hazards analysis was carried out. With respect to individual factors, the hazard ratio, 95\% confidence interval, and $\mathrm{p}$-value were calculated.

\section{Statistical analysis}

For $3 \times 2$ cross-table tests, the $\chi^{2}$ test was used. When there was a significant difference, adjustment was conducted using Holm's method, and multiple tests were performed. To compare the results among the 3 groups, analysis was conducted using Kruskal-Wallis one-way analysis of variance by ranks. The Kaplan-Meier method, log-rank test, and Cox's proportional hazards test were performed, as described above. For statistical analysis, JMP version 10.0.0 software (SAS Institute, Cary, NC) was used. A p-value of $<0.05$ was regarded as significant.

\section{Competing interests}

The authors declare that they have no competing interests.

\section{Authors' contributions}

DW and TS participated in the study design and coordination; TS, TU, DW, YN, DK, KY, YO, KH, YS, MA, and SS managed the patients and collected the data; and DW wrote the paper. All authors read and approved the final manuscript.

\section{Acknowledgements}

This work was supported by a Grant-in-Aid for Clinical Research from the National Hospital Organization to TS and a Grant-in-Aid for AIDS research from the Ministry of Health, Labor, and Welfare of Japan to DW (H24-AIDS-S-002).

\section{Author details}

${ }^{1}$ AIDS Medical Center, National Hospital Organization Osaka National Hospital, 2-1-14 Hoenzaka, Chuo-ku, Osaka City, Osaka 540-0006, Japan. ${ }^{2}$ Department of Nursing, National Hospital Organization Osaka National Hospital, Osaka, Japan.

Received: 13 July 2014 Accepted: 27 April 2015

Published online: 22 May 2015

\section{References}

1. Medley GF, Anderson RM, Cox DR, Billard L. Incubation period of AIDS in patients infected via blood transfusion. Nature. 1987;328:719-21.

2. Lui KJ, Darrow WW, Rutherford 3rd GW. A model-based estimate of the mean incubation period for AIDS in homosexual men. Science. 1988;240:1333-5.

3. Bacchetti P, Moss AR. Incubation period of AIDS in San Francisco. Nature. 1989;338:251-3.

4. Munoz A, Wang MC, Bass S, Taylor JM, Kingsley LA, Chmiel JS, et al. Acquired immunodeficiency syndrome (AIDS)-free time after human immunodeficiency virus type 1 (HIV-1) seroconversion in homosexual men. Multicenter AIDS Cohort Study Group. Am J Epidemiol. 1989;130:530-9.

5. Gras L, Geskus RB, Jurriaans S, Bakker M, van Sighem A, Bezemer D, et al. Has the rate of CD4 cell count decline before initiation of antiretroviral therapy changed over the course of the Dutch HIV epidemic among MSM? PLoS One. 2013;8, e64437.

6. Herbeck JT, Muller V, Maust BS, Ledergerber B, Torti C, Di Giambenedetto S, et al. Is the virulence of HIV changing? A meta-analysis of trends in prognostic markers of HIV disease progression and transmission. AIDS. 2012;26:193-205.

7. Muller V, Maggiolo F, Suter F, Ladisa N, De Luca A, Antinori A, et al. Increasing clinical virulence in two decades of the Italian HIV epidemic. PLoS Pathog. 2009;5, e1000454.
8. Gras L, Jurriaans S, Bakker M, van Sighem A, Bezemer D, Fraser C, et al. Viral load levels measured at set-point have risen over the last decade of the HIV epidemic in the Netherlands. PLoS One. 2009;4, e7365.

9. Crum-Cianflone N, Eberly L, Zhang Y, Ganesan A, Weintrob A, Marconi V, et al. Is HIV becoming more virulent? Initial CD4 cell counts among HIV seroconverters during the course of the HIV epidemic: 1985-2007. Clin Infect Dis. 2009;48:1285-92.

10. Dorrucci M, Rezza G, Porter K, Phillips A, Concerted Action on Seroconversion to A, Death in Europe C. Temporal trends in postseroconversion CD4 cell count and HIV load: the Concerted Action on Seroconversion to AIDS and Death in Europe Collaboration, 1985-2002. J Infect Dis. 2007;195:525-34.

11. Rangsin R, Chiu J, Khamboonruang C, Sirisopana N, Eiumtrakul S, Brown AE, et al. The natural history of HIV-1 infection in young Thai men after seroconversion. J Acquir Immune Defic Syndr. 2004;36:622-9.

12. Rangsin R, Piyaraj P, Sirisanthana T, Sirisopana N, Short O, Nelson KE. The natural history of HIV-1 subtype E infection in young men in Thailand with up to 14 years of follow-up. AIDS. 2007;21 Suppl 6:S39-46.

13. Kahn JO, Walker BD. Acute human immunodeficiency virus type 1 infection. N Engl J Med. 1998;339:33-9.

14. Sued O, Miro JM, Alquezar A, Claramonte X, Garcia F, Plana M, et al. Primary human immunodeficiency virus type 1 infection: clinical, virological and immunological characteristics of 75 patients (1997-2003). Enferm Infecc Microbiol Clin. 2006;24:238-44.

15. Lavreys L, Baeten JM, Chohan V, McClelland RS, Hassan WM, Richardson BA, et al. Higher set point plasma viral load and more-severe acute HIV type 1 (HIV-1) illness predict mortality among high-risk HIV-1-infected African women. Clin Infect Dis. 2006;42:1333-9.

16. Nakamura H, Teruya K, Takano M, Tsukada K, Tanuma J, Yazaki H, et al. Clinical symptoms and courses of primary HIV-1 infection in recent years in Japan. Intern Med. 2011;50:95-101.

17. Lindback S, Brostrom C, Karlsson A, Gaines H. Does symptomatic primary HIV-1 infection accelerate progression to CDC stage IV disease, CD4 count below $200 \times$ 10(6)/l, AIDS, and death from AIDS? BMJ. 1994;309:1535-7.

18. Vanhems P, Lambert J, Cooper DA, Perrin L, Carr A, Hirschel B, et al. Severity and prognosis of acute human immunodeficiency virus type 1 illness: a dose-response relationship. Clin Infect Dis. 1998;26:323-9.

19. Ghosn J, Deveau C, Chaix ML, Goujard C, Galimand J, Zitoun Y, et al. Despite being highly diverse, immunovirological status strongly correlates with clinical symptoms during primary HIV-1 infection: a cross-sectional study based on 674 patients enrolled in the ANRS CO 06 PRIMO cohort. J Antimicrob Chemother. 2010;65:741-8.

20. Socias ME, Sued O, Laufer N, Lazaro ME, Mingrone H, Pryluka D, et al. Acute retroviral syndrome and high baseline viral load are predictors of rapid HIV progression among untreated Argentinean seroconverters. J Int AIDS Soc. 2011;14:40.

21. Investigators ST, Fidler S, Porter K, Ewings F, Frater J, Ramjee G, et al. Short-course antiretroviral therapy in primary HIV infection. N Engl J Med. 2013;368:207-17.

22. Hogan CM, Degruttola V, Sun X, Fiscus SA, Del Rio C, Hare CB, et al. The setpoint study (ACTG A5217): effect of immediate versus deferred antiretroviral therapy on virologic set point in recently HIV-1-infected individuals. J Infect Dis. 2012;205:87-96.

23. Sucupira MC, Sanabani S, Cortes RM, Giret MT, Tomiyama H, Sauer MM, et al. Faster HIV-1 disease progression among Brazilian individuals recently infected with CXCR4-utilizing strains. PLoS One. 2012;7, e30292.

24. Grijsen ML, Steingrover R, Wit FW, Jurriaans S, Verbon A, Brinkman K, et al. No treatment versus 24 or 60 weeks of antiretroviral treatment during primary HIV infection: the randomized Primo-SHM trial. PLOS Med. 2012;9, e1001196.

25. Lodi S, Phillips A, Touloumi G, Geskus R, Meyer L, Thiebaut R, et al. Time from human immunodeficiency virus seroconversion to reaching CD4+ cell count thresholds $<200,<350$, and $<500$ Cells/mm(3): assessment of need following changes in treatment guidelines. Clin Infect Dis. 2011;53:817-25.

26. Koegl C, Wolf E, Hanhoff N, Jessen H, Schewe K, Rausch M, et al. Treatment during primary HIV infection does not lower viral set point but improves CD4 lymphocytes in an observational cohort. Eur J Med Res. 2009;14:277-83.

27. Goujard C, Bonarek M, Meyer L, Bonnet F, Chaix ML, Deveau C, et al. CD4 cell count and HIV DNA level are independent predictors of disease progression after primary HIV type 1 infection in untreated patients. Clin Infect Dis. 2006;42:709-15.

28. Langford SE, Ananworanich J, Cooper DA. Predictors of disease progression in HIV infection: a review. AIDS Res Ther. 2007;4:11. 
29. Lewden C, Thiebaut R, Boufassa F, Coulibaly A, Malateste K, Seng R, et al. Comparison of early CD4 T-cell count in HIV-1 seroconverters in Cote d'IVoire and France: the ANRS PRIMO-Cl and SEROCO cohorts. J Acquir Immune Defic Syndr. 2010;53:260-5.

30. Skar H, Albert J, Leitner T. Towards estimation of HIV-1 date of infection: a time-continuous IgG-model shows that seroconversion does not occur at the midpoint between negative and positive tests. PLoS One. 2013;8, e60906.

Submit your next manuscript to BioMed Central and take full advantage of:

- Convenient online submission

- Thorough peer review

- No space constraints or color figure charges

- Immediate publication on acceptance

- Inclusion in PubMed, CAS, Scopus and Google Scholar

- Research which is freely available for redistribution 